\title{
Investigations of Paleoclimate Variations Using Accelerator Mass Spectrometry
}

J. R. Southon, M. Kashgarian, T. A. Brown

\section{August 24, 2000}

U.S. Department of Energy

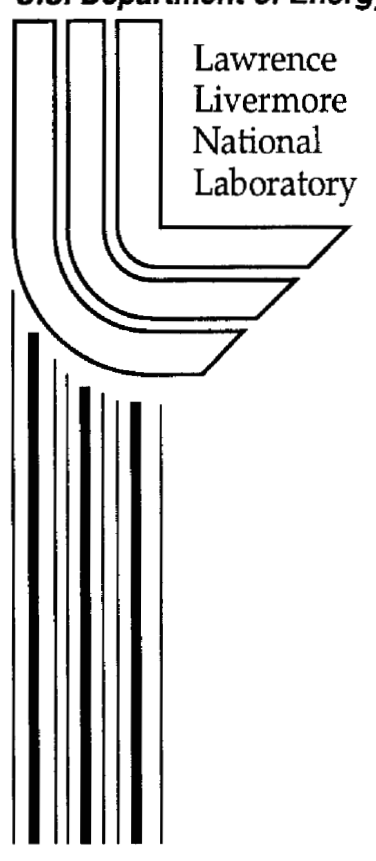




\section{DISCLAIMER}

This document was prepared as an account of work sponsored by an agency of the United States Government. Neither the United States Government nor the University of California nor any of their employees, makes any warranty, express or implied, or assumes any legal liability or responsibility for the accuracy, completeness, or usefulness of any information, apparatus, product, or process disclosed, or represents that its use would not infringe privately owned rights. Reference herein to any specific commercial product, process, or service by trade name, trademark, manufacturer, or otherwise, does not necessarily constitute or imply its endorsement, recommendation, or favoring by the United States Government or the University of California. The views and opinions of authors expressed herein do not necessarily state or reflect those of the United States Government or the University of California, and shall not be used for advertising or product endorsement purposes.

This work was performed under the auspices of the U.S. Department of Energy by the University of California, Lawrence Livermore National Laboratory under Contract No. W-7405-Eng-48.

This report has been reproduced

directly from the best available copy.

Available to DOE and DOE contractors from the

Office of Scientific and Technical Information

P.O. Box 62, Oak Ridge, TN 37831

Prices available from (423) 576-8401

http://apollo.osti.gov/bridge/

Available to the public from the

National Technical Information Service

U.S. Department of Commerce

5285 Port Royal Rd.,

Springfield, VA 22161

http://www.ntis.gov/

OR

Lawrence Livermore National Laboratory

Technical Information Department's Digital Library

http://www.llnl.gov/tid/Library.html 


\section{INVESTIGATIONS OF PALEOCLIMATE VARIATIONS USING ACCELERATOR MASS SPECTROMETRY}

\section{LABORATORY DIRECTED RESEARCH AND DEVELOPMENT}

(ERI)

Tracking code 97-ERI-009

Final report February 2000

Principal Investigator

Co-investigators

Associate director:

Administrative Unit:

Project Duration:
John R. Southon Center for AMS, L-397, LLNL (510) 423-4226 southon1@llnl.gov

Michaele Kashgarian Center for AMS, L-397, LLNL (510) 422-3703 kashgarian1@llnl.gov

Thomas A. Brown Center for AMS, L-397, LLNL (510) 423-8507 brown32@llnl.gov

Lee Younker (EES Directorate)

Center for Accelerator Mass Spectrometry (CAMS)

1 October 1996 - 30 September 1999 


\section{Introduction}

This project has used Accelerator Mass Spectrometry (AMS) ${ }^{14} \mathrm{C}$ measurements to study climate and carbon cycle variations on time scales from decades to millennia over the past 30,000 years, primarily in the western US and the North Pacific. ${ }^{14} \mathrm{C}$ dates provide a temporal framework for records of climate change, and natural radiocarbon acts as a carbon cycle tracer in independently dated records.

The overall basis for the study is the observation that attempts to model future climate and carbon cycle changes cannot be taken seriously if the models have not been adequately tested. Paleoclimate studies are unique because they provide realistic test data under climate conditions significantly different from those of the present, whereas instrumental results can only sample the system as it is today. The aim of this project has been to better establish the extent, timing, and causes of past climate perturbations, and the carbon cycle changes with which they are linked. This provides real-world data for model testing, both for the development of individual models and also for inter-model diagnosis and comparison activities such as those of LLNL's PCMDI program; it helps us achieve a better basic understanding of how the climate system works so that models can be improved; and it gives an indication of the natural variability in the climate system underlying any anthropogenically-driven changes.

The research has involved four projects which test hypotheses concerning the overall behaviour of the North Pacific climate system. All are aspects of an overall theme that climate linkages are strong and direct, so that regional climate records are correlated, details of fine structure are important, and accurate and precise dating is critical for establishing correlations and even causality. An important requirement for such studies is the requirement for an accurate and precise radiocarbon calibration, to allow better correlation of radiocarbon-dated records with calendric paleoclimate archives such as ice cores. The extension of the radiocarbon calibration back into the late Pleistocene (the period of deglaciation) thus constitutes a fifth project.

This project has been Institute-oriented in that it was only possible through collaborations with researchers from several UC campuses, and other US and foreign institutions. These collaborators have provided expertise in sampling and access to the best available paleoclimate records. In turn, CAMS scientists have provided expertise in selecting the best samples for ${ }^{14} \mathrm{C}$ measurements, and in interpreting radiocarbon results in terms of climate and carbon cycle changes, plus access to unmatched ${ }^{14} \mathrm{C}$ measurement capabilities. Project output has included climate model test data plus fundamental information on the carbon cycle and the climate system, assisting LLNL modelers (and the modeling community as a whole) to improve their simulations.

The scope of this project, and the widespread collaborations involved, have enhanced the visibility of LLNL as a focus for global climate research. This has in part led to discussions with NSF program managers on how to make LLNL researchers eligible to take part as PI's in NSF's Earth System History (ESH) 
program. For at least some proposal calls - joint ESH/NOAA programs - it appears that submission via NOAA will be possible. An initial proposal by one of us (MK) to fund coral research based on the results from an LDRD which was spun off from this one as a separate project in 1998 (see below), has been submitted under this arrangement.

\section{Scientific and technical programs}

\section{Benthic-planktonic age differences: Pleistocene vs Holocene.}

(with S. Gorbarenko, Pacific Oceanological Institute, Vladivostok, Russia; T.Oba, Hokkaido University; J.Gardner, US Geological Survey; L.Stott, USC; D.Lea and J.Kennett, UC Santa Barbara; L.Ingram, B. Roark, UC Berkeley; R. Thunell, U of South Carolina; J.McKay, University of British Columbia).

There are significant differences in the radiocarbon ages for carbonate from coeval surface- and bottom-dwelling organisms (foraminifera) preserved in ocean sediments. These offsets show the apparent age of the local bottom water relative to the surface, at the time the organisms lived. Research at CAMS and elsewhere, using these benthic-planktonic age differences as an ocean circulation tracer, has shown that water at intermediate depths $(<1000 \mathrm{~m})$ off Central California in the late Pleistocene was far better equilibrated with the atmosphere than the present-day Pacific Intermediate Water.

Our hypothesis has been that this represents the signature of ocean overturning (subduction of well-equilibrated surface water) somewhere in the North Pacific. Analogy with the present-day North Atlantic suggests that a region where surface water is pulled northward and subducts is a strong source of heat and moisture to the atmosphere and exerts a profound influence on climate. In fact, it is believed that this warming is what makes northern Europe, at the same latitude as Labrador, rather more habitable. If we can prove that such a process took place in the glacial North Pacific and pinpoint the location, we have a strong constraint on both ocean and atmospheric circulation, which models seeking to reproduce the late Pleistocene climate must reproduce.

We have studied the extent of this water mass to determine its source by measuring benthic-planktonic age differences in North Pacific cores.

Measurements from the far NW Pacific off Kamchatka, the Bering Sea, the Sea of Okhotsk and the Gulf of Alaska (all of which have been suggested as possible sources) show no sign of its presence, and a mid-Pacific source may be most likely. Results from sites off British Columbia, and in the Santa Barbara Basin and off central California, are in preparation as portions of the Ph.D. theses of Jennifer McKay (UBC) and Brendan Roark (UC Berkeley).

\section{Long-term lake sediments records in the western US}

(with L.Benson, US Geological Survey, S. Mensing, U. Nevada-Reno, S. Lund, USC)

Our study of lake paleoclimate records complements our other research in 
paleoceanography and the paleo-carbon cycle. Our primary goal has been to use AMS 14C dates to establish high resolution chronologies for lake core climate records from the western Great Basin, eastern Sierra Nevada and other North American lakes. We can then correlate the terrestrial climate events such as low lake level stands, alpine glaciationss, and changes in precipitation patterns and vegetation with climate events preserved in marine sediments and ice cores (eg, the so-called Heinrich events).

We have published work on Owens, Mono, and Pyramid Lake climate records. The number and relative timing of Sierra Nevada alpine glacial events recorded in lake sediments correspond closely to the North Atlantic marine Heinrich events, suggesting that there may be rapid hemisphere-wide response to climate forcing. This in turn suggests a fast atmospheric coupling rather than slow propagation via the deep ocean circulation, and this finding challenges climate models to reproduce this atmospheric link.

\section{Eastern Pacific upwelling: millennial changes. \\ (with T.Baumgartner, Scripps/UCSD; R.Francis, D.Holmgren, U. of Washington, D.Fedje, Canadian Heritage)}

Any model seeking to simulate climate on a centennial-to-millennial scale must reproduce the natural variations which occur on these time scales, or changes due to natural variability may be erroneously attributed to human intervention. We have studied this variability in a 1700-year record of deep-water upwelling in sediments from the Santa Barbara Basin off California. The annual layers (varves) in these anoxic sediments provide an absolute time scale, and ${ }^{14} \mathrm{C}$ levels in carbonate from marine organisms preserved in the sediments are used as a tracer to infer paleoceanographic conditions. Our results show that strong variations in upwelling of ${ }^{14} \mathrm{C}$ - depleted deep water occurred over the period corresponding to the Little Ice Age in Europe, superimposed on a longer-term decrease.

One possible cause of such upwelling changes is that they are related to longterm variations in the position and intensity of the North Pacific High and the Aleutian Low. Today, variations of this sort occur on decadal and shorter time scales (e.g, the North Pacific "regime shift" of the mid-70's, el Nino/non el Nino differences, and summer/winter variations). A strong Aleutian Low moving eastward into the Gulf of Alaska "spins up" the subarctic circulation and promotes open-ocean upwelling in that system, while the resulting onshore winds further south suppress coastal upwelling along the California coast. Therefore, if this hypothesis of similar but longer-term changes is correct, upwelling variations in the subarctic Pacific (eg, Gulf of Alaska) should be anticorrelated with those in Santa Barbara.

To test this theory, we have undertaken ${ }^{14} \mathrm{C}$ measurements on terrestrial and marine materials from partially laminated sediments obtained from an anoxic basin in Effingham Inlet on the west coast of Vancouver Island, British Columbia, Canada, in collaboration with researchers from the University of Washington. The terrestrial dates, combined with ${ }^{210} \mathrm{~Pb}$ dating, have provided the basis for 
correlating the laminations between the various cores that were obtained during the coring cruise and provided an underlying chronological framework for the decadal resolution depositional history.

Our collaborators also extracted marine based materials such as fish scales, as part of the fisheries Ph.D. project of grad student Diego Holmgren (to be completed this summer) to study past variations in numbers of preserved scales from commercially important species such as herring, sardine, hake, and anchovy, and infer past variations in stock strengths over the past 700 years. We are measuring ${ }^{14} \mathrm{C}$ in these marine samples to determine the upwelling strength of ${ }^{14} \mathrm{C}$-depleted, nutrient-rich waters from below the surface mixed layer. Not only is the upwelling strength significant for fisheries studies as an indicator of nutrient availability, but the strength of coastal upwelling is related to ocean basin atmospheric circulation patterns as outlined above. This allows us to test our ideas on the climatological state of the eastern North Pacific over the past millennium.

\section{Century -scale Severe Climate Events in the California Sierra} and the Americas during the Last Two Millennia. (with S. W. Stine, Cal State Hayward, G.Brush, Johns Hopkins University)

Our studies of extreme climate events occurring in the California Sierra and the Americas during the last two thousand years have been undertaken in a collaborative effort with Prof. S. W. Stine of California State University Hayward. The primary goal of our activities has been to utilize advanced ${ }^{14} \mathrm{C}$ dating techniques ("wiggle-matching" - the precise fitting of sequences of radiocarbon dates on tree rings to calibration data sets) to establish chronologies for the event sequences that are accurate and reliable to within a few decades. Such precision is essential in attempting to understand the interrelationships between severe century-scale climate events recorded in widely separated locations throughout the Americas.

In the initial stages of this work, ring sequences from submerged tree stumps found preserved and rooted in growth position in lakes and rivers in the California Sierra were measured. The results, which were presented at the 15th International Radiocarbon Conference, have provided decadal-precision calendar year ages for the terminations of two of the major drought events in the California Sierra previously recognized by Prof. Stine. Subsequent measurements of samples from the California Sierra and other US locations have been directed towards defining the geographical range of these, and possibly related, extreme climate events within the continental US, and towards identifying and providing precise calendar year ages for all of the California Sierra drought events.

As a part of the these efforts, we have collaborated with Dr. G. Brush Johns Hopkins University) in studying a climatically anomalous period recorded in Chesapeake Bay sediments. The ${ }^{14} \mathrm{C}$ dating results we have obtained indicate that this "Chesapeake Bay" event occurred synchronously with the California 
Sierra drought event which ended at about $1210 \mathrm{AD}$, indicating that the "1210 $A D^{\prime \prime}$ event had a geographical range of effect that was at least of continental scale (G. Brush et al., ms in preparation).

In addition to these continental US studies, we have also collaborated with Prof. Stine in studies of climate variations over the last two millennia in southern Patagonia. Our activities have centered on the precise dating of rooted-in-place tree stumps and other materials which were buried under lake sediments that were deposited subsequent to lake level rises induced by advances of Andean glaciers. Our initial measurements have identified several glacial advance/lake level rise events during the last ten thousand years. In particular, in addition to our US based results which provide evidence of a century-scale severe climate event of continental scale which ended at about $1210 \mathrm{AD}$, the preliminary data from Patagonia suggest a significant climate anomaly occurred there about 300 years ago that was synchronous with a severe drought event in the California. Our research activities in this area will continue under current funding and new proposals by Prof. Stine to NSF and Argentina's CONICET.

\section{Radiocarbon calibration for deglaciation}

(with K. Hughen, Harvard; J. Overpeck, NOAA; L.Petersen, U of Miami; S.Lehman, U of Colorado)

Since ${ }^{14} \mathrm{C}$ concentrations in the atmosphere have varied over time, a calibration curve is required to convert from radiocarbon to calendar ages. Such a curve is essential for a detailed picture of the last glacial-to-interglacial climate switch between 14500 and 11500 years ago - a change which is still not well understood.

A detailed calibration data set based on ${ }^{14} \mathrm{C}$ dating of wood of known age (determined by tree ring counting) spans the past 11800 years. In FY97 we extended this back another 3000 years at 100-year resolution, by dating carbonate from marine organisms (foraminifera) preserved in annually layered (varved) ocean sediments, from the Cariaco Basin off Venezuela. We related changes in the curve to variations in ocean circulation in papers in Nature and Radiocarbon. In FY98 we began to study fine structure in the record by resampling the sediment cores with improved resolution and reduced measurement uncertainties. We completed this record at half-resolution early in FY99 and have now pushed this to full (10- to 20-year) resolution over the entire 3000 years. The full dataset is shown in Fig 1. A calibration curve for the halfresolution data, based on a preliminary layer count and a marine-terrestrial radiocarbon offset which is assumed to be identical to that of the recent past is shown in Fig 2. Fig 2 also shows the oldest part of the tree ring calibration, plus the fit of our floating varve chronology to the tree ring data.

The calibration data of Fig 2 show dramatic changes in slope corresponding to variations in the ${ }^{14} \mathrm{C}$ content of the atmosphere, due to changes in ocean circulation. The most dramatic of these occurred during the Younger Dryas cold period $12900-11600 \mathrm{BP}$ (years Before Present) when climate returned to almost full glacial conditions over large areas of the northern hemisphere. A second steepening of the curve at $14050 \mathrm{BP}$ corresponds to the Older Dryas (an earlier 
cold event in Europe which has also been linked to ocean circulation changes), and the plateau prior to $14100 \mathrm{BP}$ may be related to the Allerod warming - the initial climate amelioration following the glacial maximum. The changes in ${ }^{14} \mathrm{C}$ associated with the onset of the cold events occurred in 100 years or less, indicating that the circulation changes that drove them took place at least this quickly (and probably much faster). The challenge to climate models is now to reproduce these very rapid variations.

We are currently refining the blank corrections and resolving some minor discrepancies in the record by running replicates, and preparing the final layer count. The high-resolution results will be submitted to Science for publication in the spring and a methods paper will be presented at the 17th International Radiocarbon conference in June. We have also carried out some preliminary measurements on a longer core reaching back to $50,000 \mathrm{BP}$, which show that even more dramatic ${ }^{14} \mathrm{C}$ variations took place before $25,000 \mathrm{BP}$. We will use these results as the basis for a proposal to NSF ESH in the next funding cycle.

\section{5a. Ice core chronologies}

Variations in the annual sediment layers in the Cariaco cores are closely correlated with variations in numerous paleoclimate proxies preserved in Greenland ice cores, suggesting that linkages between these polar and tropical records are rapid and direct. While investigating these correlations as part of the calibration project, we gained new insight into the differences between the layercount time scales derived from two major ice core studies in the 1990's. These differences represent a critical problem for attempts to understand the fundamental question of why the climate system changed from a glacial to an interglacial state 10-15,000 years ago. Since innumerable paleoclimate records are cross-linked with one or other of these inconsistent chronologies, many issues of synchronicity and causality in past rapid climate changes will be almost impossible to resolve until they are reconciled.

Offsets between the chronologies had been assumed to be a result of the progressive accumulation small errors in identifying and counting annual layers. Our work has shown that, to the contrary, the offsets back to $14,500 \mathrm{BP}$ occur over two short 100-200 year periods. The fact that the slip is localized suggests that whatever the cause, the problem is potentially solveable. A draft of our finding, to be submitted to Geophysical Research Letters, is included as Appendix A of this report.

\section{Corals as water mass tracers.}

Both the upwelling intensity and the transport of water across the equatorial Pacific are key elements influencing the El Niño cycle and thereby the global climate. In the first year of this ERI project we began development of a new application of AMS $\Delta^{14} \mathrm{C}$ : the use of high resolution/high precision $\Delta^{14} \mathrm{C}$ in coral growth bands as a tracer of surface water circulation in the tropics. Our objective has been to produce continuous time series of high resolution (monthly to 
seasonal) $\Delta^{14} \mathrm{C}$ measurements several decades in length from key sites which document spatial and temporal $\triangle 14 C$ variability in the tropical Pacific. Although the measurement of other chemical and isotopic species in coral skeletons can be used to determine environmental conditions, only $\Delta^{14} \mathrm{C}$ has the potential to be used as a tracer of $>$ dynamic circulation.

In the first phase of the project we demonstrated our ability to perform high precision $( \pm 3 \%)$ measurements and examined the source water masses which flow from the Pacific to the Indian Ocean via the Indonesian Seaway. (Moore et al., 1997). It rapidly became clear that the results justified greatly increasing the scope of the project to provide coverage across the entire tropical Pacific, and in year 2, it was expanded to a separate ERI (98-ERI-002).

\section{Technical development.}

This work has generated continuing pressure for a high throughput of precise radiocarbon dates, many on samples more than two half-lives old, and we have taken the opportunity to push the operation of the LLNL spectrometer closer to its limits to improve throughput. A series of small but critical ion source modifications financed from internal CAMS development funds significantly improved the source reliability. This stability allowed us to test the effects of running the ion source with higher sputtering voltages and beam energy. We found that the system could be run harder with no loss of measurement quality; indeed, the measurement precision and accuracy for radiocarbon dates have improved significantly due to our ability to acquire better counting statistics in reasonable times. We also tested a new iron catalyst for converting $\mathrm{CO} 2$ samples to the solid graphite required by the ion source. This reduced graphitization times by $30-50 \%$ and also further improved ion source output. As a result, typical radiocarbon dating precisions have improved significantly over the three-year span of this project and throughput has increased $30-50 \%$. 


\section{Refereed publications}

Benson, L., J. Burdett, S. Lund, M. Kashgarian, and S. Mensing, 1997, Nearly synchronous climate change in the Northern Hemisphere during the last glacial termination: Nature, v. 388, p. 263-265. UCRL-JC-136604

Benson, L. V., J. P. Smoot, M. Kashgarian, A. SarnaWojcicki, and J. W. Burdett, 1997, Radiocarbon ages and environments of deposition of the Wono and Trego Hot Springs tephra layers in the Pyramid Lake Subbasin, Nevada: Quaternary Research, v. 47, p. 251-260.

UCRL-JC-133299

Black, D. E., L. C. Peterson, J. T. Overpeck, A. Kaplan, M. N. Evans, and M. Kashgarian, 1999, Eight centuries of North Atlantic Ocean atmosphere variability: Science, v. 286, p. 1709-1713. UCRL-JC- 138798

Hughen, K. A., J. T. Overpeck, S. J. Lehman, M. Kashgarian, and J. R. Southon, 1998, A new C-14 calibration data set for the last deglaciation based on marine varves: Radiocarbon, v. 40, p. 483-494. UCRL-JC-133356

Hughen, K. A., J. T. Overpeck, S. J. Lehman, M. Kashgarian, J. Southon, L. C. Peterson, R. Alley, and D. M. Sigman, 1998, Deglacial changes in ocean circulation from an extended radiocarbon calibration: Nature, v. 391, p. 65-68. UCRL-JC-133358

Moore, M. D., D. P. Schrag, and M. Kashgarian, 1997, Coral radiocarbon constraints on the source of the Indonesian throughflow: Journal of Geophysical Research-Oceans, v. 102, p. 12359-12365. UCRL-JC-136539

Ortiz, J., A. Mix, S. Hostetler, and M. Kashgarian, 1997, The California current of the last glacial maximum: Reconstruction at 42 degrees $\mathrm{N}$ based on multiple proxies: Paleoceanography, v. 12, p. 191-205. UCRL-JC-133300

\section{Conference presentations and abstracts}

Brown, T.A. and S.W. Stine, 1996, Calibrated ages for severe medieval Droughts in California, 15th International Radiocarbon Conference, UCRL-JC-126055

Southon, J.R., K.Hughen and C.Herring, 1998, A detailed radiocarbon calibration for the Bolling-Allerod-Younger Dryas, 8th International AMS Conference, UCRL-JC-136668

Baumgartner, T.R. , J.Southon, 1996, A 1500-year radiocarbon record of nearsurface ocean reservoir ages obtained from the varved sediments of the Santa Barbara Basin, California, EOS 77 p298, UCRL-JC-133208 Abs 


\section{Figure captions}

Figure 1. The full-resolution Cariaco radiocarbon data set of radiocarbon age vs depth below the sediment surface, spanning $5 \mathrm{~m}$ of core sampled at $1.5 \mathrm{~cm}$ intervals. Each sample represents a date obtained from approximately 2000 foraminfera picked from the sediment. Where possible, specimens of a single species (G. bulloides) were identified and picked for dating. Where foram numbers were sparse, samples of mixed planktonic (surface-dwelling) species were used.

Figure 2. Half-resolution Cariaco radiocarbon calibration: radiocarbon ages vs true age derived from counting annual layers. The Cariaco data has been corrected for marine-terrestrial radiocarbon offsets, using recent known-age foraminifera from the core top, under the assumption that the 425-year offset has remained constant. The "floating" Cariaco data has been spliced into the existing tree ring calibration by least-squares fitting over the period 10800-11800 BP. 


\title{
Appendix A
}

\section{Towards a reconciliation of the deglacial GRIP and GISP2 ice core chronologies}

\author{
John Southon
}

Center for AMS, L-397, Lawrence Livermore National Laboratory, Livermore, CA 94551 9900

Draft prepared for submission to Geophysical Research Letters

\begin{abstract}
Offsets between the GISP2 and GRIP ice core chronologies over the past 14500 years do not accumulate gradually, but appear over two short intervals of 100-200 years. An initial offset of 80 years occurs close to 3300-3400 BP (years Before Present), and another 100 years of slip appears at the start of the Younger Dryas.
\end{abstract}

\section{Introduction.}

Two of our most valuable paleoclimate archives are the GISP2 and GRIP ice cores, drilled $30 \mathrm{~km}$ apart at Summit, Greenland in the early 1990 's. The $\mathrm{d}^{18} \mathrm{O}$ records from the cores (Grootes et al., 1993; Stuiver et al., 1995; Johnsen et al., 1992; Dansgaard et al., 1993) are crucial because they are used extensively for cross-correlating the annual layer ice core time scales with uncalibrated paleoclimate sequences from marine and terrestrial archives, thereby providing a global time framework for the Pleistocene - Holocene transition. However, efforts to understand deglaciation and rapid climate change are hampered by the fact that the two chronologies disagree, by 80 years at the early Holocene $8200 \mathrm{BP}$ cold event and at the end of the Younger Dryas, and by 200 years at the start of the Bølling Interstadial (Fig 1).

An obvious hypothesis is that the offsets are due to the accumulation of small errors in identifying and counting annual layers, but surprisingly, this is not the case. In this paper I review evidence from cosmogenic isotopes and ice core acidity records which identifies an interval of divergence in the late Holocene. I then use $\mathrm{d}^{18} \mathrm{O}$ data to further constrain this slip to a period around 3300-3400 BP, and to recognize a second discrepancy at the start of the Younger Dryas. These short intervals supply almost all of the offset between the two chronologies over the past 14500 years.

\section{GISP2 and GRIP chronologies for deglaciation}

The GISP 2 chronology was constructed using $\mathrm{d}^{18} \mathrm{O}$ measurements, visual stratigraphy, laser scattering from particulates, and electrical conductivity to identify annual layers (Alley et al, 1997, Meese et al., 1997). Layer counting was continuous back to 40,000 BP except for short breaks (typically corresponding to 10 years or less) due to core loss, mostly in the brittle ice zone ca. 3000-9000 BP. The lengths of these lost sections were known from drill logs, and layer thicknesses were interpolated to estimate the number of lost years (Alley et al., 1997).

The ss09 time scale, the most widely used of the three GRIP chronologies (Johnsen et al., 1992; Dansgaard et al, 1993; Hammer et al., 1997), was determined back to 8600 BP by correlating volcanic acid fall-out horizons with corresponding features in the layer-counted South Greenland Dye 3 core (Hammer et al, 1986). Before 8600 BP, seasonal variations in concentrations of microparticles and several chemical species were counted to establish an 
annual chronology back to $14500 \mathrm{BP}$. A relationship between $\mathrm{d}^{18} \mathrm{O}$ and ice accumulation rate was assumed and an ice flow model was used to estimate layer thinning (Dansgaard et al., 1993). A combination of the modeling results and tie points from the layer count were then used to develop the final time scale (Johnsen et al., 1992; S. Johnsen, pers. comm.).

Both chronologies explicitly define the zero BP time point as 1950, not the start of ice drilling in 1989, so none of the offset is due to differences in age conventions.

\section{Volcanic acidity spikes}

Acidity records from GISP2, GRIP and Dye 3 contain volcanic sulphate spikes which can be detected by measurements of electrical conductivity (ECM) or sulphate concentrations (Clausen et al., 1997, Zielinski et al., 1994). Large peaks at 2000 \pm 3 BP and $3028 \pm 5$ BP are essentially synchronous in all 3 cores, but GISP2-GRIP correlations around 3400-3500 BP and earlier in the 4th millennium BP are less obvious. A group of four sulphate peaks spanning 3391-3409 BP in GISP2 can be correlated with Dye 3 ECM peaks at 3389,3406 and 3412 BP, but the GRIP record contains only one large ECM peak in this region, at 3374 BP. ECM peaks at 4001 and 3994 BP, in Dye 3 and GRIP respectively, have no obvious counterpart in GISP2.

Which of four major GISP2 sulphate spikes between 3550 and 3650 BP corresponds to intense GRIP and Dye 3 ECM singlets, at 3585 and 3593 BP respectively, is a question linked to the continuing debate over possible associations between acidity peaks, cold/wet climate anomalies in tree rings from $3577 \mathrm{BP}$, and the Minoan eruption of Thera/Santorini (e.g., Zielinski and Germani, 1998; Manning 1998; and references therein). Baillie (1996), Clausen et al. (1997), and Zielinski and Germani (1998) select peaks at 3619 BP, 3645 BP and 3573 BP, respectively, as the GISP2 features which correlate best with some or all of the eruption, the climate event, or the ECM peaks, on grounds which are discussed in detail in those papers. In summary, the relationship between the GISP2 and GRIP acidity records for this period remains an open question.

\section{GISP2 ${ }^{10} \mathrm{Be}$ vs tree ring ${ }^{14} \mathrm{C}$}

${ }^{10} \mathrm{Be}$ and ${ }^{14} \mathrm{C}$ are both produced in the atmosphere by cosmic rays, but deposition of $10_{\mathrm{Be}}$ is prompt, with an atmospheric lifetime of about one year (Raisbeck et al., 1981), while the recycling of ${ }^{14} \mathrm{C}$ via exchange between carbon reservoirs causes atmospheric ${ }^{14} \mathrm{C}$ concentrations $\left(\Delta^{14} \mathrm{C}\right)$ to lag centennial-scale production changes. Carbon cycle models predict that tree ring records of atmospheric ${ }^{14} \mathrm{C}$ fluctuations should lag ice core $10 \mathrm{Be}$ variations by 15-20 years (Bard et al., 1997; Stuiver and Braziunas, 1993), and a 15-year shift has been seen over the past 1000 years in Antarctic ice (Bard et al., 1997). However, the GISP2 record of ${ }^{10} \mathrm{Be}$ concentrations, which currently extends back from $3400 \mathrm{BP}$ (Finkel and Nishiizumi, 1997), leads the tree ring $\Delta^{14} \mathrm{C}$ record (Stuiver et al., 1998) by 75 years back to $11300 \mathrm{BP}$ (Fig. 2). Beyond that time, the ${ }^{10} \mathrm{Be}$ record is perturbed by large accumulation rate changes.

As Finkel and Nishiizumi (1997) and Bard et al. (1997) have observed, this offset has real significance, because the dendro- time scale for the ${ }^{14} \mathrm{C}$ record is probably accurate to within a year back to 10400 BP (Spurk et al., 1998; Kromer and Spurk, 1998; Stuiver et al., 1998). It seems unlikely that the carbon cycle has changed enough over the Holocene to invalidate the model results, so the 75 year ${ }^{10} \mathrm{Be}-{ }^{14} \mathrm{C}$ offset implies that the GISP2 chronology is 60 years too old before $3400 \mathrm{BP}$. (Conversely, the early Holocene GISP2GRIP offset of 80 years suggests GRIP could be a decade or two too young). The \pm 10 to 20 year stability of this ${ }^{10} \mathrm{Be}-{ }^{14} \mathrm{C}$ shift over 8000 years is remarkable, and suggests that 
the cumulative precision of the GISP2 time scale is far better than the incremental counting uncertainty of 1-2\% (Alley et al, 1997, Meese et al., 1997).

\section{GISP2-GRIP d18O: the Holocene}

Fig 3 shows GISP2 d ${ }^{18} \mathrm{O}$ data ( $35-40 \mathrm{~cm}$ per sample) and GRIP 55-cm results, smoothed with 11-point and 7-point running means respectively to ca. 25-year resolution. Tentative correlations are shown, and I have shifted segments of the GRIP record chronologically and plotted them over the GISP2 data to illustrate the quality of the fits. The plot extends from the period where acidity spikes show good agreement between the two chronologies, well into the period where $10 \mathrm{Be}$ indicates GISP2 is too old.

GRIP data shifted by -20 years (ie, to younger ages) fit the GISP 2 results reasonably well over most of the period 1800-2500 BP. Gaps in the GISP data at 2340 and 2400 BP are at least partly responsible for the relatively poor fit in the interval $2300-2400 \mathrm{BP}$. The two records also correspond closely over the period 2900-3300 BP with minimal shifting, and the region of agreement may extend almost to $3600 \mathrm{BP}$ (but see below). The GRIP record from $3600 \mathrm{BP}$ to almost $4400 \mathrm{BP}$ also bears a striking resemblence to the GISP2 data, but only when shifted by 80 years to older ages. Thus, the comparison suggests an offset of several decades before the middle of the 4th millennium BP, but close agreement in more recent times.

The correlations are by no means perfect. The two records bear little resemblence over the period 2500-2900 BP, a result which is surprising but not unprecedented: Stuiver et al. (1995) cite other instances of lack of correlation and local variation in $\mathrm{d}^{18} \mathrm{O}$ from Greenland cores. Also, significant "accordioning" occurs around $4450 \mathrm{BP}$ : the offset changes from 80 years to 35-50 years, and a prominent double peak at 4400 BP in GRIP appears to collapse to a single peak at 4440 BP in GISP2.

Furthermore, the relationship between the two records over the critical $3300-3600 \mathrm{BP}$ period is ambiguous. The problem is exacerbated by a gap in the GISP2 results from 3420 to $3450 \mathrm{BP}$ and possibly also by the fact that GISP2 $\mathrm{d}^{18} \mathrm{O}$ data from 3484 to $3648 \mathrm{BP}$ required correction for fractionation due to evaporation from stored water samples (Stuiver et al., 1995). Two alternatives are shown in Fig 3. A minimal ( -5 year) shift applied to the GRIP data captures most of the variations in the GISP2 record at least to $3300 \mathrm{BP}$ and perhaps almost to $3600 \mathrm{BP}$, as stated earlier. However, GRIP data for 3330 to $3580 \mathrm{BP}$ also closely resemble the GISP2 record when offset by 100 years - a shift at least roughly consistent with the 60 years indicated by the ${ }^{10} \mathrm{Be}-14 \mathrm{C}$ comparison at $3400 \mathrm{BP}$.

In spite of these imperfections, the balance of the $\mathrm{d}^{18} \mathrm{O}$ evidence suggests a fundamental change around $3300-3600 \mathrm{BP}$, from chronologies that agree to within a decade or so to chronologies that are significantly offset .

\section{GISP2-GRIP d ${ }^{18}$ O: the Younger Dryas}

Figs 1 and 4 shows comparisons between the 55-cm GISP2 and 20-year GRIP d ${ }^{18} \mathrm{O}$ data for the Bølling-Allerød-Younger Dryas. Allowing for minor differences due to finite sampling density and averaging, the agreement between the two records over this period is very good, with one major exception: an obvious slip of 100 years at the very start of the Younger Dryas. Also shown in Fig 4 are 5-year GRIP data (S.Johnsen, pers. comm.) smoothed to 10-year resolution and shifted to the ss09 timescale. They indicate that GISP2 and GRIP have similar $\mathrm{d}^{18} \mathrm{O}$ structure over the period of slip, ie, the problem is not missing core or other "block" data loss. Rather, the GRIP core lacks half the annual layers throughout this interval, or the GISP2 ice contains many sub-annual structures which mimic annual bands, or one of the layer counts is erroneous. 


\section{Conclusions}

GISP2-GRIP chronological offsets back to 14500 BP appear in two short intervals. Acidity correlations show that the two time scales agree back to $3000 \mathrm{BP}$, and $\mathrm{d}^{18} \mathrm{O}$ data extend the agreement beyond $3300 \mathrm{BP} .{ }^{10} \mathrm{Be}-1{ }^{14} \mathrm{C}$ comparisons show that the GISP2 chronology is 60 years too old before $3400 \mathrm{BP}$, implying that any slip occurs near 3300$3400 \mathrm{BP}$. The $\mathrm{d}^{18} \mathrm{O}$ results confirm that an 80 -year offset is present before $3600 \mathrm{BP}$. The acidity evidence is inconclusive, but at least one interpretation is consistent with an offset at 3600 BP. $\mathrm{d}^{18} \mathrm{O}$ data show an extra 100 year divergence at the start of the Younger Dryas.

Several further studies could help confirm or disprove these findings. First, ongoing work to extend the GISP2 ${ }^{10} \mathrm{Be}$ record (R.Finkel, pers. comm.) will determine the $10_{\mathrm{Be}}$ ${ }^{14} \mathrm{C}$ shift for prominent ${ }^{14} \mathrm{C}$ peaks at 2300 and $2700 \mathrm{BP}$. Second, if the GISP2 record is indeed offset before $3400 \mathrm{BP}$, the identification by Clausen et al. (1997) of the $3644 \mathrm{BP}$ GISP2 sulphate peak with the 3590 BP GRIP and Dye 3 ECM peaks may be correct. Examination of ice from these three peaks for tephra shards of a common composition, regardless of whether this matches any postulated Theran source, would be instructive.

However, any definitive answers will probably come from reexamination of the actual chronological data. The fact that slip between the two time scales is localized suggests that further scrutiny by GISP2 and GRIP investigators of ice, core logs, and other records corresponding to these short periods would potentially be of great benefit.

Acknowledgements. GISP2 $55 \mathrm{~cm}$ and GRIP 20 -year $\mathrm{d}^{18} \mathrm{O}$ data were obtained from: World Data Center A for Paleoclimatology, National Geophysical Data Center, Boulder, Colorado. Higher resolution data were provided by the Quaternary Isotope Laboratory, University of Washington, Seattle, and by S. Johnsen. I thank Sigfus Johnsen, Richard Alley, Piet Grootes, Mike Baillie, and Bob Finkel for helpful discussions. This work was supported by Lawrence Livermore National Lab (LDRD 97-ERI-009) and by the US DOE under contract W-7405-Eng-48.

\section{References.}

Alley, R.B. et al., 1997, Visual-stratigraphic dating of the GISP2 ice core: Basis, reproducibility and application, J. Geophys. Res. 102, 26367-26381.

Baillie, M.G.L., 1996, Extreme environmental events and the linking of the tree-ring and icecore chronologies, in Tree Rings, Environment and Humanity, J.S.Dean, D.M.Meko and T.W.Swetnam eds, Radiocarbon 1996, pp703-711

Bard, E., G.M.Raisbeck and J.Jouzel, 1997, Solar modulation of cosmogenic nuclide production over the last millennium: comparisons between ${ }^{14} \mathrm{C}$ and ${ }^{10} \mathrm{Be}$, Earth Plan. Sci. Lett. 150, 453-462.

Clausen, H., et al., 1997, A comparison of the volcanic records over the past 4000 years from the Greenlnd Ice Core Project and Dye 3 Greenland ice cores, J. Geophys. Res. $102,26707-26723$

Finkel, R.C. and K.Nishiizumi, 1997, Beryllium 10 concentrations in the Greenland Ice Sheet Project ice core from 3-40ka, J. Geophys. Res. 102, 26699-26706.

Grootes, P.M. et al., 1993, Comparison of oxygen isotope reuslts from the GISP2 and GRIP Greenland ice cores, Nature 366, 552-554.

Hammer, C.U., H.B.Clausen and H.Tauber, 1986, Ice-core dating of the Pleistocene/Holocene boundary applied to the calibration of the ${ }^{14} \mathrm{C}$ time scale, Radiocarbon 28, 284-291. 
Hammer, C.U. et al., 1987, The Minoan eruption of Santorini in greece dated to 1645 BC?, Nature 328, 517-519.

Hammer, C.U. et al., 1997, The stratigraphic dating of the GRIP Ice Core, special report, Geophys.Dept, Niels Bohr Inst. for Astron. Phys. and Geophys, Univ. of Copenhagen, Copenhagen.

Johnsen, S.J. et al., 1992, Irregular glacial interstadials recorded in a new Greenland ice core, Nature 359, 311-313.

Kromer, B. and M.Spurk, 1998, Revision and tentative extension of the tree-ring based ${ }^{14} \mathrm{C}$ calibration 9200-11855 cal BP, Radiocarbon 40, 1117-1125

Manning, S., 1998, Correction. New GISP2 ice-core evidence supports 17 th century BC date for the Santorini (Minoan) eruption: response to Zielinski and Germani (1998), J. Arch. Sci. 25, 1039-1042

Meese, D.A. et al., 1997, The Greeneland Ice Sheet Project 2 depth-age scale: methods and results, J. Geophys. Res. 102, 26411-26423.

Raisbeck, G.M. et al., 1981, Cosmogenic ${ }^{10} \mathrm{Be} /{ }^{7} \mathrm{Be}$ as a probe of atmospheric transport processes, Geophys. Res. Lett. 8, 1015-1018.

Spurk, M. et al., 1998, Revisions and extensions of the Hohenheim oak and pine chronologies: new evidence about the timing of the Younger Dryas/Preboreal transition, Radiocarbon 40, 1107-1116.

Stuiver, M., and T.F.Braziunas, 1993 , Sun, ocean, climate and atmospheric ${ }^{14} \mathrm{CO}_{2}$ : an evaluation of causal and spectral relationships, The Holocene 3, 289-305.

Stuiver, M., P.M.Grootes and T.F.Braziunas, 1995, The GISP2 $\mathrm{d}^{18} \mathrm{O}$ climate record of the past 16500 years and the role of the sun, ocean and volcanoes, Quaternary Research 44, 341-354.

Stuiver, M. et al., 1998, INTCAL98 radiocarbon age calibration 24000-0 cal BP, Radiocarbon 40, 1041-1083.

Zielinski, G.A. et al., 1994, Record of volcanism since 7000BC from the GISP2 Greenland ice core and implications for the volcano-climate system, Science 264, 948-952.

Zielinski G.A. and M.S.Germani, 1998, New ice core evidence challenges the 1620's BC age for the Santorini (Minoan) eruption, J. Arch. Sci. 25, 279-289.

\section{Figure Captions}

Figure 1. GISP2 and GRIP $\mathrm{d}^{18} \mathrm{O}$ data (as per mil deviations from the the PDB standard) for the period 8000-15000 BP , showing offsets between the two chronologies.

Figure 2. a) GISP2 ${ }^{10} \mathrm{Be}$ concentrations (arbitrary units) vs the INTCAL98 $\Delta^{14} \mathrm{C}$ record (Stuiver et al., 1998) for 3000-8000 BP, showing a constant offset of 75 years.

b) As for a), for the older section of Holocene GISP2 ${ }^{10} \mathrm{Be}$ data.

Figure 3. $\mathrm{d}^{18} \mathrm{O}$ data for 1800-5200 BP. Segments of the GRIP data have been shifted to correct for estimated GISP2-GRIP chronological offsets and superimposed on the GISP2 results. Two possibilities are shown for the period 3300-3600 BP.

Figure 4. $\mathrm{d}^{18} \mathrm{O}$ data for $11000-13500 \mathrm{BP}$, showing the increase in GISP2-GRIP offset at the start of the Younger Dryas. Detailed GRIP data (shown superimposed) closely resemble the GISP2 record over the period of slip. 
Figure 1

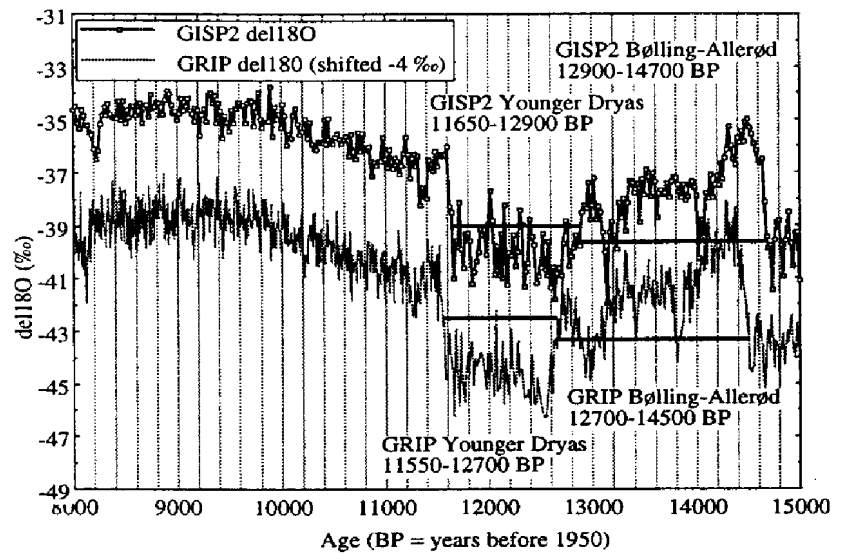

Figure 2(a) and (b)
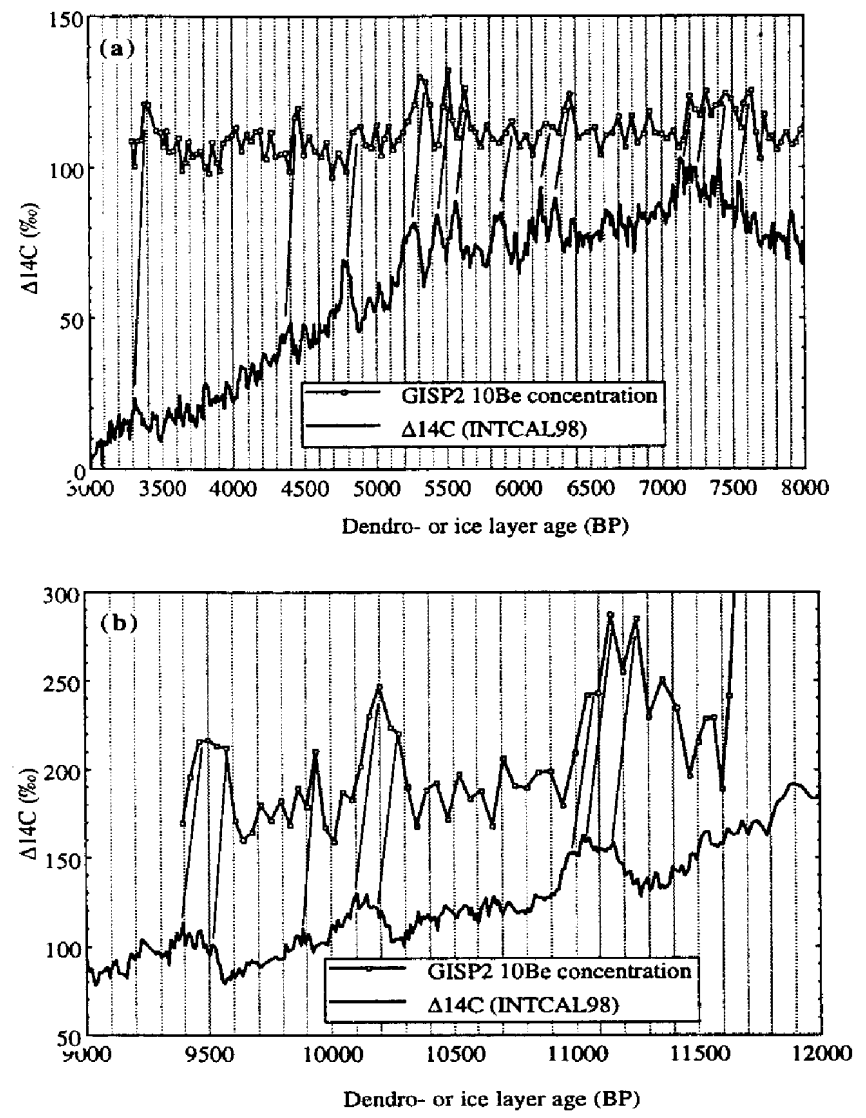


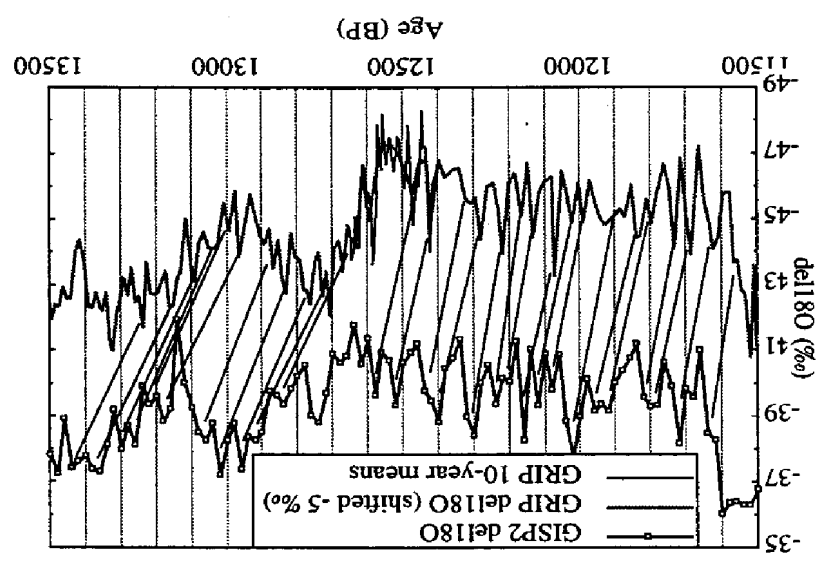

† ว.Inถิ!ม

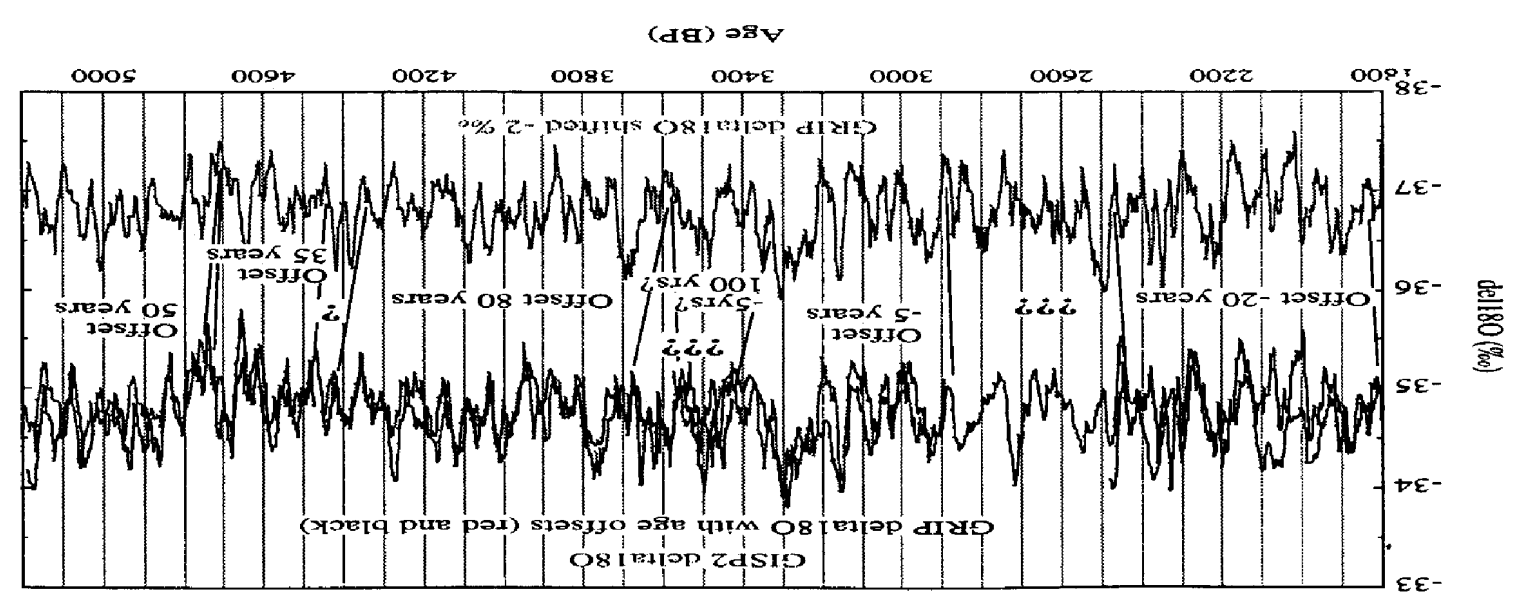

$\mathcal{E}$ ว.กถรก! 
